\title{
Molecular Phylogeny in 3-D
}

\author{
M. Milner ${ }^{1}$, A.G. Bansode ${ }^{2}$, A.L. Lawrence ${ }^{3}$, S.A. \\ Nevagi $^{1}$, V. Patwardhan ${ }^{4}$, and S.P. Modak ${ }^{1,5}$ * \\ 1Department of Zoology, Karnatak University, Dharwad, \\ 580003, India \\ ${ }^{2}$ Ahmednagar College, Ahmednagar, India \\ ${ }^{3}$ Centre for Life Sciences Biotechnology \& Bioinformatics, \\ Poona Business School, C-5 Varsha Park, Baner Road, \\ Pune 411019, India \\ ${ }^{4}$ ARI, Pune 411004, India \\ ${ }^{5}$ Open Vision, 759/75 Deccan Gymkhana, Pune 411004, \\ India
}

\begin{abstract}
Molecular phylogenetic trees are constructed in three dimensions relative to the distribution of MW and $\mathrm{pl}$ classes and immunocrossreactivity against polyclonal antibodies to lens crystallins, as well as multiple sequence alignment between amino acid sequences, coding nucleotide sequences and the gene nucleotide sequences for $\beta$-globin. Euclidian distances are estimated to position species in $x, y, z$ space by multidimensional scaling and merged with bootstraptested branching pattern of Fitch \& Margoliash plots to obtain 3-D phylogenetic tree. Compared to single attributes, phylogenetic trees based on multiple parameters allow significant repositioning of rodents, chiroptera and primates.
\end{abstract}

\section{Introduction}

Since Darwin (1859), phylogenetic trees of living organisms have been constructed on the basis of palaeontological, morphological, embryological, physiological, ecological, genetic (Myer, 1970) and, more recently, molecular evidence, often dealing with single trait/character. The distinction between two nearest species depends on changes in multiple parameters before one can establish their near-neighborly or genealogical position. Although data are available for polypeptide amino acid sequences, their biochemical properties and immunocrossreactivity as well as nucleotide sequences of many genes and their RNA intermediates, two dimensional phylogenetic trees are constructed based on one attribute using unweighted pairs grouping (Fitch and Margoliash, 1967) or maximum likelihood (see, for review, Schadt et al., 1998). Thus, depending on the parameter, the same species/strain often places at different distance and position within the same test group (Patwardhan, 1992; Milner et al., 2003). For example, a tree based on manipulated or restricted nucleotide sequence offers number of solutions for even relatively simple genomes like HIV (Rambaut et al., 2001). The degenerate triplet code, coding sequences interrupted

*For correspondence. Email spmodak@rediffmail.com. by introns, alternate splice sites and variable promoter sequences in genes make it difficult to fit sequence data in a uniparametric trees. Here we display and discuss and apply a multiparametric method (Milner et al., 2003) to construct phylogenetic trees based on (a) biochemical and immunocrossreactive properties of vertebrate lens crystallins and (b) sequence data for the gene, cDNA and polypeptide for $\beta$-globin. The 3-D trees can be viewed from any angle each furnishing better understanding of the relative position and evolutionary distance of each species.

\section{Data and Methodology}

Electrophoretic profiles of MW and pl of 18 vertebrate lens crystallins, their isoelectric focusing pattern and immunocrossreactivity to polyclonal antibodies against crystallins of the mouse, chiropterans Rousettus leschnaulti or Megaderma lyra (Bansode, 1985; Patwardhan, 1990; Patwardhan et al., 1990, 1992) were compared to estimate similarity coefficients (S value) (Brown et al., 1979) by the equation [ $\mathbf{S}=\mathbf{Z}$ I $(\mathbf{X}+\mathbf{Y}-\mathbf{Z})$ ], where, the similarity coefficient $S=$ fraction of shared bands, $X=$ total number of bands in species $A, Y=$ total number of bands in species $B$ and $Z=$ number of bands common to species $A$ and $B$ and the number of changes per molecule ( $P$ value) (Upholt, 1977; Brown et al., 1979) by the equation $\mathbf{P}=\mathbf{-}[\operatorname{lnS}] / \mathbf{N}$, where $\mathrm{N}$ is 3 for $\alpha, \beta$, and $\gamma$ or $\delta$ crystallins, InS is the natural logarithm of $S$ value. The phylogenetic trees were constructed by unweighted pair groupings method (Fitch and Margoliash, 1967; King \& Jukes, 1969; Goodman et al., 1971) using the software Mega (Molecular evolutionary genetics analysis software, MEGA version 2.1, S.Kumar, et al., 2001). In case of immunocrossreactivity the reactivity was estimated by the equation $\mathbf{R}=\mathbf{Z} / \mathbf{X}$ where $\mathbf{R}=$ reactivity, $Z=$ the number of precipitin lines in the heterologous reaction and $X=$ the number of precipitin lines in the homologues reaction. From the reactivity, $\mathrm{P}$ values were calculated by the equation $\mathbf{P}=-[\ln R] / \mathbf{N}$, where $\mathrm{N}$ is 3 for $\alpha, \beta$, and $\gamma$ or $\delta$ crystallins, $\operatorname{lnR}$ is the natural logarithm of $R$ value. We compared vertebrate lens crystallins from Shark (Scoliodon sorrakowah, order Lamniformes, subclass Chondropterygii, Class Pisces), Pomfret (Pampus argenteus, order Perciformes, Subclass Teleostei, Class Pisces), Frog (Rana tigerina, order Anura, Class Amphibia), Garden lizard (Calotes versicolour, order Lacertilia, Class Reptilia), Chick (Gallus domesticus, order Galliformes, Class Aves), Mouse (Mus musculus, order Rodentia, Class Mammalia), Rat (Rattus norvegicus, order Rodentia, Class Mammalia), Bandicoot (Bandicota indica, order Rodentia, Class Mammalia), Squirrel (Funambulus pennanti, order Rodentia, Class Mammalia), 4 microchiroptera with 3 species under the Genus Hipposideros (Hipposideros speoris, Hipposideros bicolor, Hipposideros cineraceus, sub-order Microchiroptera, order Chiroptera, Class Mammalia), Miniopterus (Miniopterus schreibersii, suborder microchiroptera, order Chiroptera, Class Mammalia), 


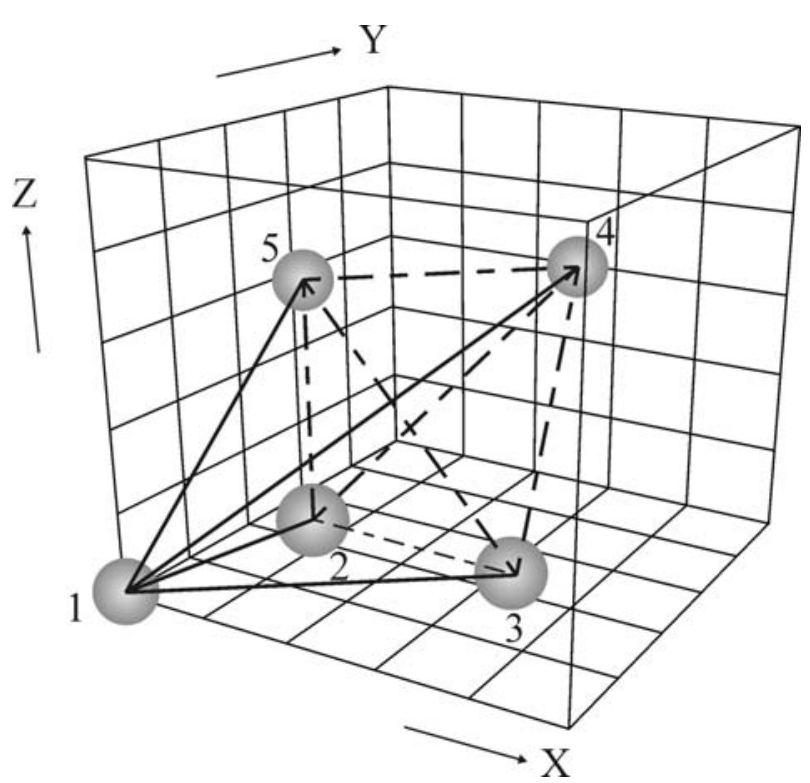

Figure 1. A schematic drawing showing "star" (_ _ $)$ Euclidian distances between the species (spheres) at the origin $(0, \overline{0,0})$ and those in the 3-D space, and "network" ( _ _ _ ) Euclidian distances among different species excluding that at the origin.

Megaderma (Megaderma lyra, sub-order Microchiroptera, order Chiroptera, Class Mammalia) and Taphozous (Taphozous longimanus, sub-order microchiroptera, order Chiroptera, class Mammalia), megachiroptera Rousettus (Rousettus leschnaulti, sub-order megachiroptera, order chiroptera, class Mammalia), Pteropus (Pteropus giganteus, sub-order megachiroptera, order chiroptera, class Mammalia), and Cynopterus (Cynopterus sphinx, suborder megachiroptera, order chiroptera, class Mammalia)

Table 1. Euclidean (star) distances in 3-D plots relative to distribution IC against polyclonal antibodies to lens crystallins from 3 mammals, pl and MW.

\begin{tabular}{|l|c|c|c|}
\hline Species & Mouse & Rousettus & Megaderma \\
\hline H. cineraceus & 0.174 & 0.236 & 0.253 \\
\hline H. speoris & 0.170 & 0.217 & 0.250 \\
\hline H. bicolor & 0.187 & 0.248 & 0.262 \\
\hline Miniopterus & 0.173 & 0.205 & 0.242 \\
\hline Megaderma & 0.071 & 0.106 & 0.000 \\
\hline Taphozous & 0.079 & 0.041 & 0.035 \\
\hline Rousettus & 0.089 & 0.000 & 0.076 \\
\hline Cynopterus & 0.076 & 0.076 & 0.090 \\
\hline Pteropus & 0.076 & 0.076 & 0.072 \\
\hline Mouse & 0.000 & 0.192 & 0.071 \\
\hline Rat & 0.182 & 0.268 & 0.189 \\
\hline Bandicoot & 0.142 & 0.292 & 0.139 \\
\hline Squirrel & 0.162 & 0.193 & 0.246 \\
\hline Chick & 0.902 & 1.090 & 0.948 \\
\hline Calotes & 0.876 & 0.955 & 0.905 \\
\hline Frog & 0.750 & 0.975 & 0.819 \\
\hline Shark & 0.950 & 1.399 & 0.934 \\
\hline Pomfret & 0.848 & 1.302 & 0.836 \\
\hline
\end{tabular}

to obtain the similarity co-efficient [S] or R values and number of changes per protein $[\mathrm{P}]$. The $\mathrm{P}$ values for $\mathrm{MW}$ and $\mathrm{pl}$ of 18 vertebrates were subjected to unweighted pair grouping as above to obtain the phylogenetic trees. The $P$ values for precipitin lines after crossreacting against three polyclonal antisera in immunoelectrophoresis were plotted in $X, Y$ and $Z$ axes in a $3-D$ space (Figure $1 b$, c; Megaderma, not shown). Using the formula $D=\sqrt{ }\left\{\left(\mathbf{x}_{1}-\mathbf{x}_{2}\right)^{2}\right.$ $\left.+\left(y_{1}-y_{2}\right)^{2}+\left(z_{1}-z_{2}\right)^{2}\right\}$, where $D$ is the Euclidian distance between two species and $\left(\mathrm{x}_{1}, \mathrm{y}_{1}, \mathrm{z}_{1}\right) \&\left(\mathrm{x}_{2}, \mathrm{y}_{2}, \mathrm{z}_{2}\right)$ are the 3-D coordinates for any two species, "star" and "network" Euclidian distances were estimated from these 3-D plots as shown in Figure 1. Star distances are those between the species at origin $(0,0,0)$ and others in the $x, y$, and $z$ 3-D space while the "network" distances are those among all species within the $\mathrm{x}, \mathrm{y}$, and $\mathrm{z}$ space excluding the one at the origin. The data are expressed with SD whenever applicable (Table 1) Phylogenetic trees were constructed using Mega software as before and assessed by 1000 normal bootstrap trials (Efron, 1979; Felsenstein, 1985) to obtain estimates of the probability and confidence limit calculated by the formula $C L=P \pm 1.96 \sigma$, where $C L$ is the Confidence limit, $\mathrm{P}$ is the probability of observing trees similar to mean distances tree and the $\sigma=\sqrt{ }(\mathbf{P}(\mathbf{1 - P}) / \mathbf{n}$ for n number of samples.

From the "star" distances a 3D plot was constructed using the "star" distances of between mouse antigenantibody homologues reaction as reference $(0,0,0)$, 17 heterologous anti-mouse reactions on $\mathrm{x}$-axis, antiRousettus reaction on $y$-axis and anti-Megaderma reaction along z-axis. The Euclidian distances were measured between all pairs from these 3D plots and processed by unweighted pair grouping method to obtain phylogenetic relationship between 18 species. In the 3D plot the species were joined in stem-branch formation as in the phylogenetic tree (Milner et al., 2003). Phylogenetic trees were constructed from the network distances alone as well as "star + network" distances. Mean Euclidian network + star distances (Table 2) were subjected to MDS (version 1.13, http://www.let.rug.nl/Okleiweg/levenshtein, Multidimensional scaling) to fix individual species in an $\mathrm{X}, \mathrm{Y}, \mathrm{Z}$ space. The 3-D distances between all pairs were re-estimated from MDS plot and the stem-branch pattern obtained from the constructed phylogenetic tree was merged with the MDS plot. The Euclidian distances reestimated from the MDS plots, were compared with the actual distances to determine the standard error. MDS plots give single measurement of Euclidean distance so that confidence limits were not estimated.

Amino acid sequence of $\beta$-globin polypeptide, the coding nucleotide sequence (cDNA) for $\beta$-globin and the gene nucleotide sequence were scanned from NCBI (http://www.ncbi.nlm.nih.gov/). Only 12 species yielded all 3 attributes for $\beta$-globin, which were then retrieved namely the primates the Human (Homo sapiens, order Primates, class Mammalia), Gorilla (Gorilla gorilla, order Primates, class Mammalia) and Tarsius (Tarsius syrichta, order Primates, class Mammalia), Rabbit (Oryctolagus cuniculus, order Lagomorpha, class Mammalia), the Ungulates namely Bovine (Bos taurus, order Artiodactyla class Mammalia) and Goat (Capra hircus, order Artiodactyla class Mammalia), the rodents including Mouse (Mus musculus, order 


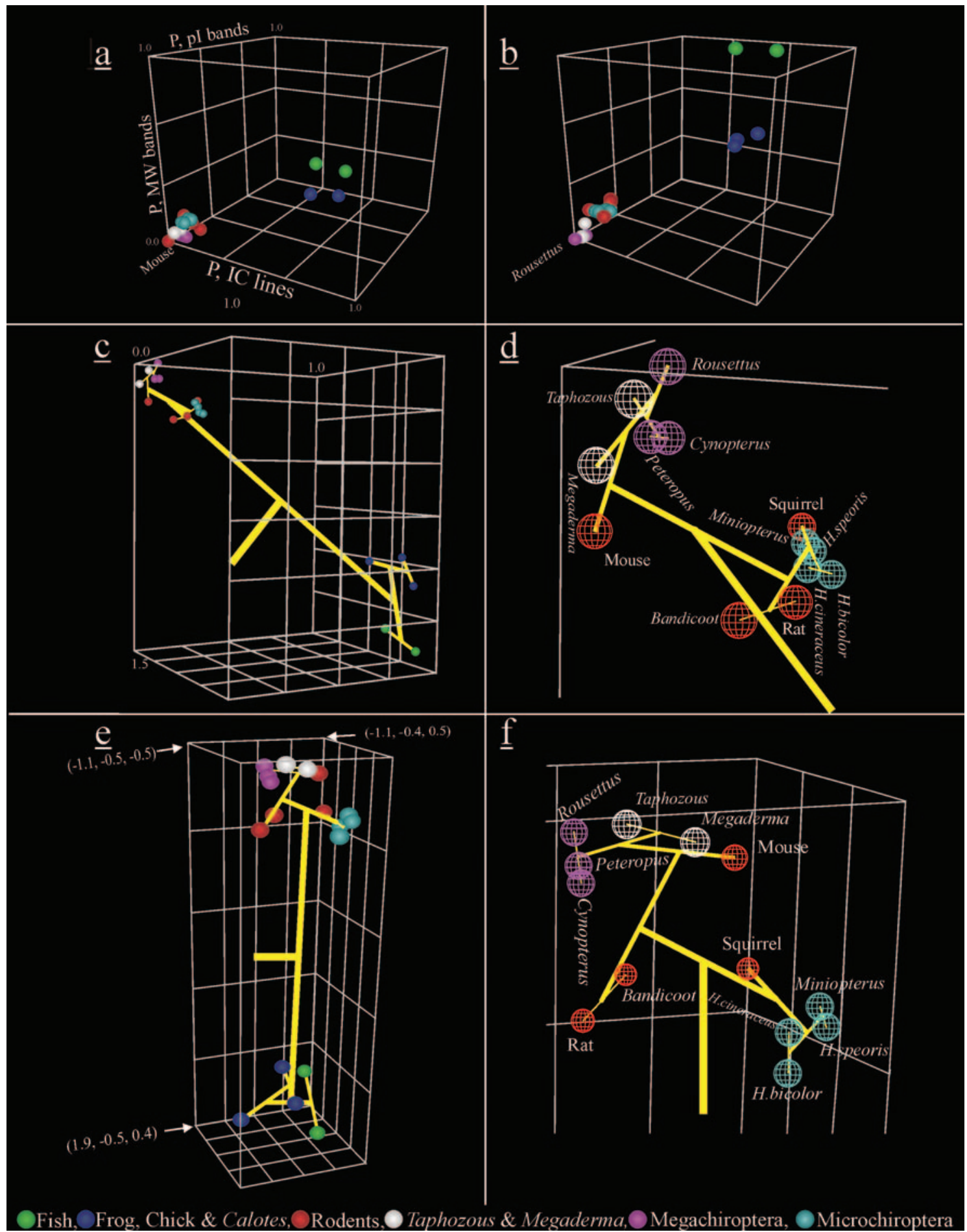

Figure 2. Three-dimensional molecular phylogenetic trees for lens crystallins (a-f). [a] positioning species in 3-D against $\mathrm{P}$ values for distribution of pl (y axis), crystallin immunocrossreactivity (IC) against antibody to mouse crystallin ( $x$ axis) and $M W$ ( $Z$ axis) of crystallins; [b] positioning species in against $P$ value of crystallin pl, MW and IC against antibody to Rousettus crystallin (x axis); [c] 3-dimensional repositioning of "star" Euclidian distances in a, b and anti-Megaderma plots along ' $X$ ', ' $Y$ ' and ' $Z$ ' axes, respectively. Species are joined by transposing the nearest-neighbor data in Figure $3 c$ to form the tree with the stem positioned midway between mammals and lower vertebrates. The thickness of the Stem decreases as one moves towards mammalian species. [d] A magnified view of the distal portion of the 3-D tree in $\mathrm{c}$ and slightly rotated showing the right cluster with 3 megachiroptera, mouse and presumed microchiroptera Taphozous sp. and Megaderma sp., while 4 microchiroptera and squirrel form a separate cluster to the left. Notice the distinct blossoms with Cynopterus and Pteropus which is farthest away from those bearing Bandicoot and rat, or microchiroptera under genus Hipposideros,. Also notice that the diameter of a sphere (species position) is largest for the species immediately in the foreground and smallest when farther away. [e] a 3-D tree based on MDS of "network + star" distances in $x, y$ and $z$ space- again species positions were joined as in the 2-dimensional phylogenetic tree in Figure 3e; [f] magnified and slightly rotated view of the mammalian branches in $2 \mathrm{e}$ again showing a discrete clusters for mega- and microchiroptera as in $\mathrm{d}$ and distinct blossoms for Taphozous and Megaderma along with megachiroptera and away from that for microchiroptera. Notice the rat and Bandicoot pair near mouse and megachiroptera unlike in $\mathrm{d}$. 

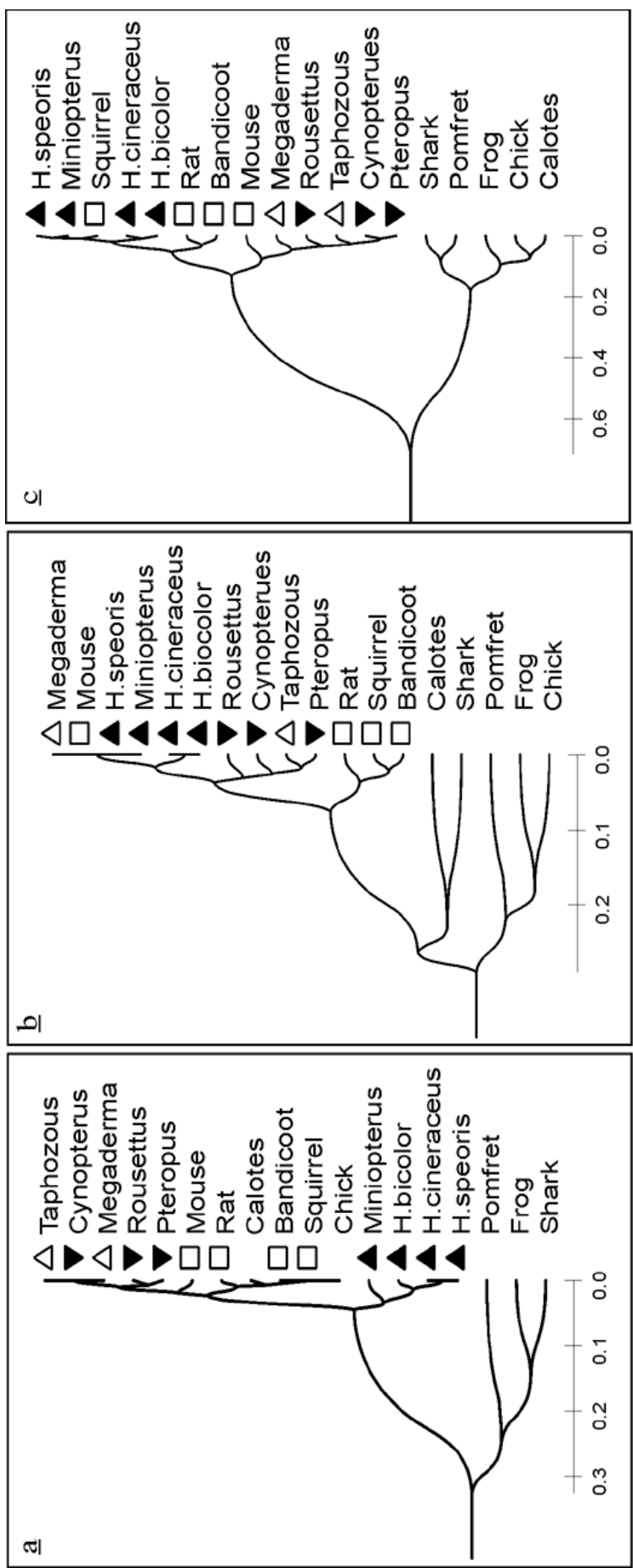
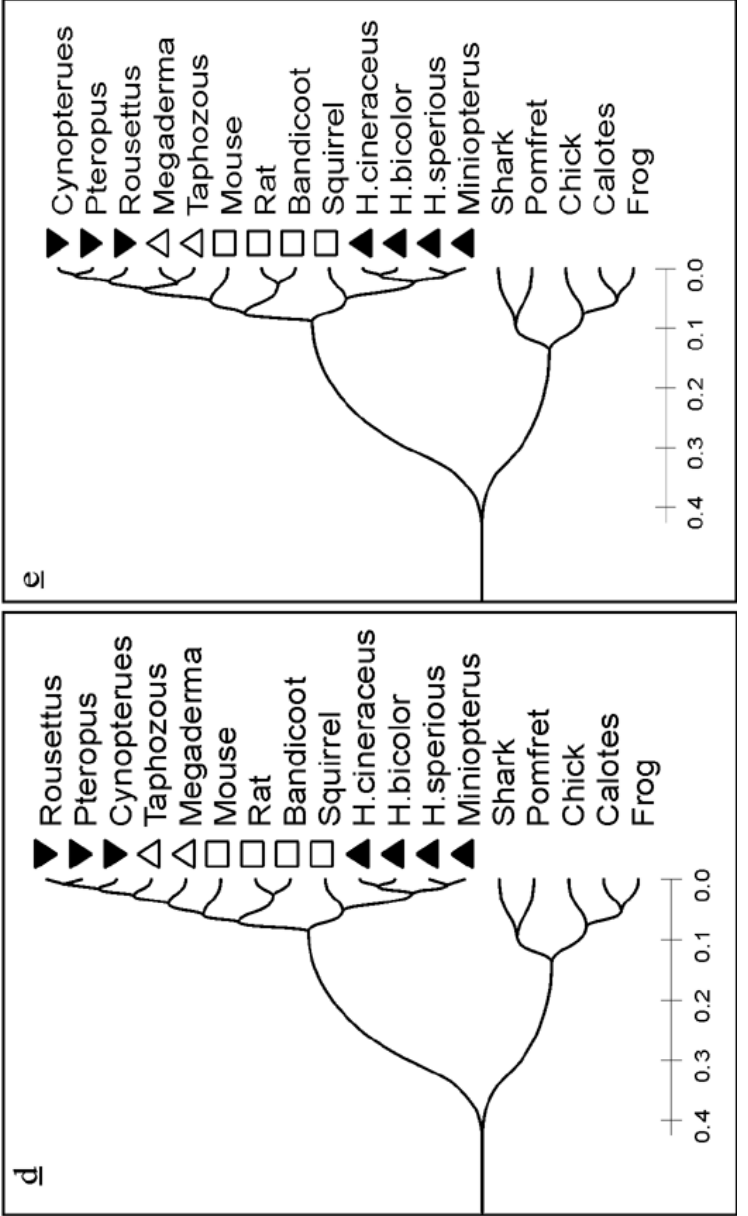

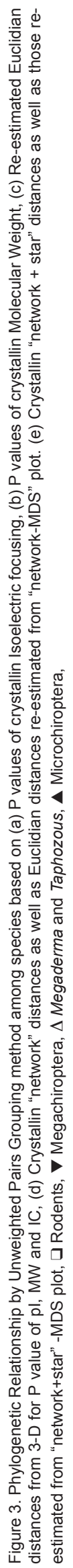




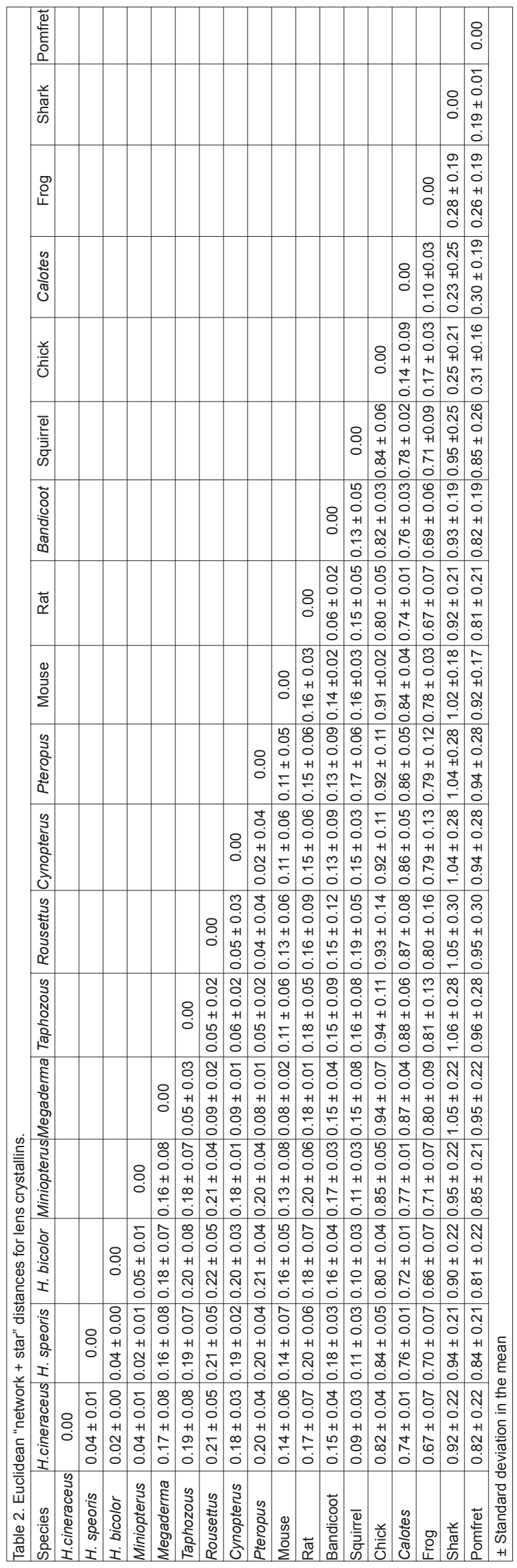

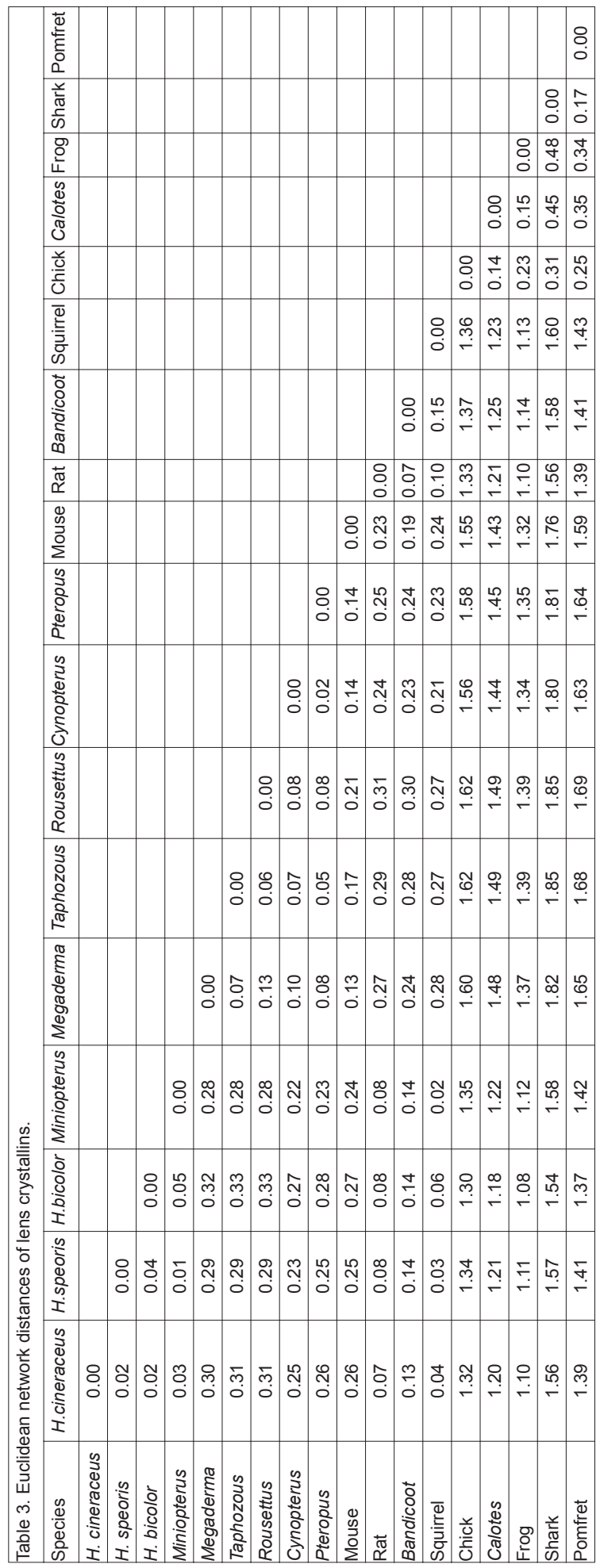




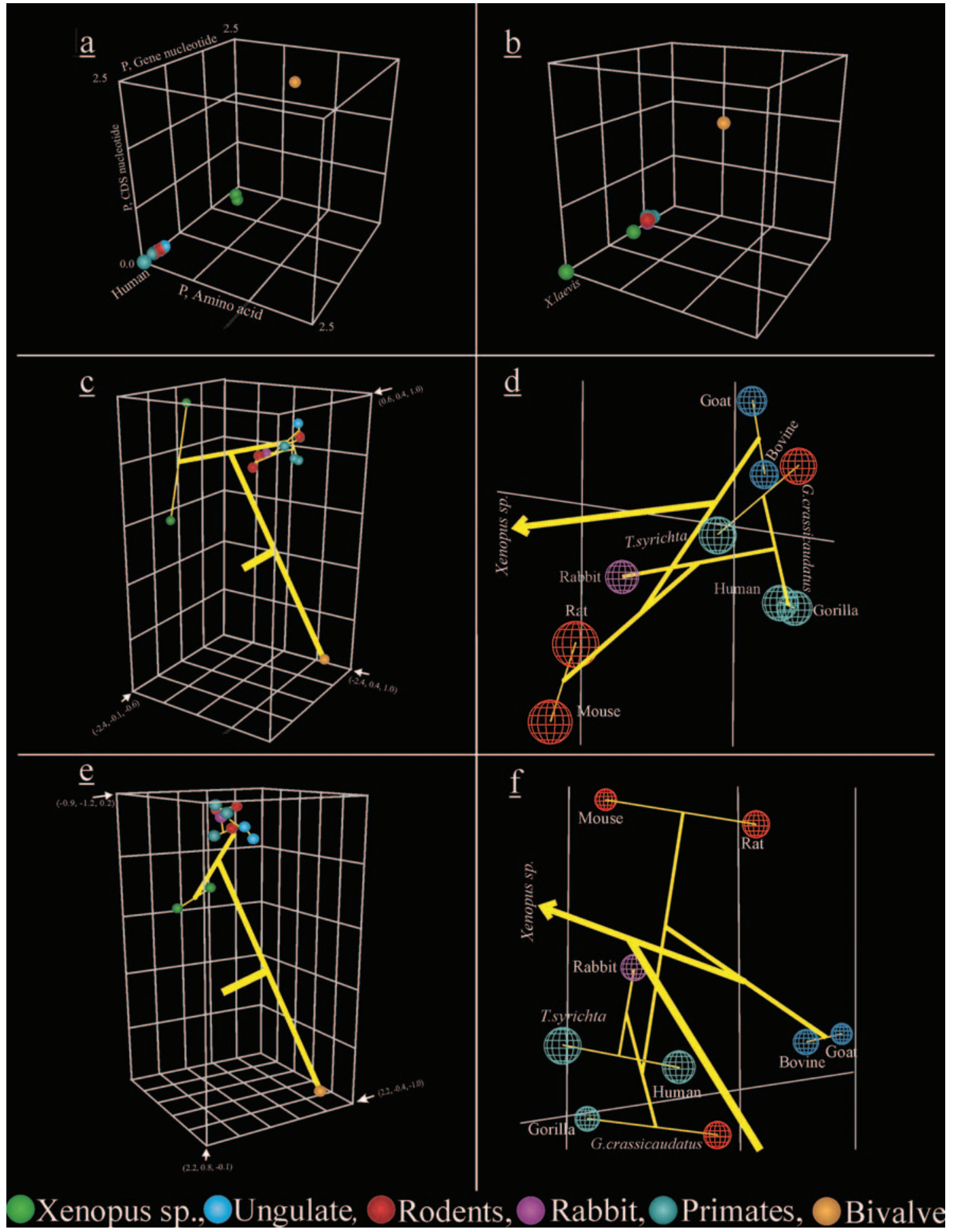

Figure 4. Three-dimensional molecular phylogenetic trees for $\beta$-globin. [a] $P$ values derived from the MSA of human (positioned at $0,0,0) \beta$-globin gene nucleotide sequence ( $y$ axis), $\beta$-globin coding nucleotide sequence $(z$ axis) and $\beta$-globin amino acid sequence ( $x$ axis) against 11 other species; [b] MSA comparison in 3-D as in h but against Xenopus laevis $\beta$-globin (at 0,0,0); [c] 3-D plot of "star" Euclidian distances by MDS combined with the phylogenetic tree in Figure 5d. [d], a magnified and slightly rotated view of the mammalian branch and sub branches positioning primate-blossom with the rodent $G$. crassicaudatus and distant from rat-mouse, and cow-goat blossoms. [e] 3-D MDS of "network + star" Euclidian distances combined with phylogenetic tree in Figure 5h. [f] a magnified and slightly rotated view of mammalian branch with primate and G. crassicaudatus (rodent) blossoms distant from rat-mouse and ungulates. 
Rodentia, Class Mammalia), Rat (Rattus norvegicus, order Rodentia, Class Mammalia) and Dormouse (Graphiurus crassicaudatus, order Rodentia, Class Mammalia), two species under the Genus Xenopus (Xenopus laevis, and Xenopus tropicalis, Order Anura Class Amphibia), and the bivalve Anadara (Anadara trepezia, order Arcoida, Class Pteriomorphia, Phylum Mollusca). The gene sequences were scored beginning with 5' proximal TATA box till the 3 ' polyadenylation site and inclusive of exons and introns. Data for all pairs were subjected to multiple sequence alignment (MSA) by CLUSTALW (Thompson et al., 1994) to estimate the percent similarity coefficient and $P$ values as above. Similarly, coding nucleotide sequence and polypeptide amino acid sequences were subjected to MSA to obtain P values. Individual phylogenetic trees were constructed from $P$ values for the amino acid sequence, gene nucleotide sequence and the coding nucleotide sequence. With a different reference species at the position $(0,0,0)$, species were positioned in 12 different 3-D plots with $P$ for amino acid sequence on $x$ axis, $P$ for coding nucleotide sequence on $y$-axis and gene nucleotide sequence on $z$-axis and examples of human, mouse, $X$. laevis and A. trepezia are shown in Figure 1. From each plot Euclidian "star" and "network" distances were estimated as before (Figure 1a) along with standard deviation distances wherever applicable. The phylogenetic trees were constructed with "network" and "star + network" distances were tested by bootstrap as before. The "star" or "network + star" distances were then used to fix each species in a 3-dimensional space by MDS and, from reestimated Euclidian distances, the branching pattern in the phylogenetic tree was merged with the MDS plot. The standard error was calculated as before.

\section{Results and Discussion}

Vertebrate lens crystallin homology

First, we have plotted $\mathrm{P}$ values among $\mathrm{pl}$, MW immunocrossreactivity (IC) of vertebrate crystallins against polyclonal antibodies to mouse (Figure 2a) Rousettus (Figure 2b) or Megaderma (not shown). Euclidian distances were estimated and the "star" distance data are shown in Table 1 while the combined Euclidian "network" and "star" distances are shown in Table 2. From the network distances alone (not shown) and "network + star" distances (Table 1) phylogenetic trees were constructed (Figure $3 d-e)$, tested by bootstrap which gave the probability of fit with confidence limit of $0.73 \pm 0.039$ for trees using "network" as compared to $0.61 \pm 0.043$ for "network + star" distances. The phylogenetic trees were also constructed for individual attributes pl (Figure 3a) and MW (Figure 3b) that exhibit the substantially different genealogical arrangement as compared to the trees based on multiple parameters. We then plot in 3-D Euclidean "star" distances (Table 1) for mouse (x-axis), Rousettus (y-axis) and Megaderma (zaxis) (Figure 2c). Euclidian distances were re-estimated among all pairs of species (Table 3 ) from which another phylogenetic tree is constructed (Figure 3c) and resulting connectivity is transposed over the 3-D plot in Figure $2 c$ to obtain a 3-D phylogenetic tree. Thus, from the hypothetical vertebrate stem, mammals cluster on one branch, which is farther away from that leading to other vertebrates. A magnified view (Figure $2 \mathrm{~d}$ ) shows that the mammalian cluster further bifurcates with the closer one bearing the mouse, Taphozous, Megaderma and all megachiroptera while the Rat, Bandicoot, Squirrel and microchiroptera Miniopterus and 3 species under the Genus Hipposideros, are positioned further away over the second branch. The closer branch then bifurcates between mouse and the remaining chiroptera blossom separately in the sequence Megaderma, Rousettus and Taphozous on one hand, and the Cynopterus-Pteropus pair on the other. Thus, Taphozous and Megaderma, previously classified as microchiroptera on the basis of classical taxonomic and geographic considerations (Romer 1945, Suthers et.al. 1970, Honacki et.al. 1982), may actually be closer to the megachroptera \& mouse and distant from the sub-branches with Bandicoot and rat, 3 species under Genus Hipposideros, and squirrel. The data in Table 2 are subjected to MDS in order to position the 18 species in $\mathrm{x}$, $y, z$ space (Figure 2e-f). The Euclidian distances (Table 4) from the resultant $x, y$ and $z$ coordinates were used to reconstruct the phylogenetic tree (Figure $3 \mathrm{e}$ ) and the branching pattern was again transposed to visualize a 3$D$ tree (Figure 2e,f). This tree also exhibits segregation of mammals from other vertebrates and the mammalian stalk bifurcates into the closer one bearing squirrel, Miniopterus and 3 species under Genus Hipposideros while further away on the second branch are sequentially positioned the rodents followed by Taphozous and Megaderma while the Pteropus, Cynopterus and Rousettus (megachiroptera) blossom out further away. We again conclude that Megaderma lyra and Taphozous longimanus are probably closer to Megachiroptera than the Microchiroptera and probably constitute the link between the latter and Rodentia. Most microchiroptera are cave dwelling and insectivorous with a well developed echolocation apparatus. Taphozous and Megaderma do not share the last two attributes with microchiroptera in addition to being distant in terms of the distribution $\mathrm{pl}, \mathrm{MW}$ and of crystallins and IC to 3 distinct antigens. We, therefore, reclassify Taphozous and Megaderma under the sub-order megachiroptera or as a separate suborder minichiroptera.

The phylogenetic tree based on "network" distances for 5 parameters or attributes, namely, pl, MW, and IC to mouse antiserum, Rousettus antiserum and Megaderma antiserum (Figure $3 d$ ) is in all essential features similar to that for MDS "network + star" distances, while those based on unique attributes such as MW (Figure 3a) or pl (Figure $3 b$ ) are considerably different. For example, from pl (Figure 3a), the lizard Calotes and the chick position on the rodent-megachiroptera branch while from MW (Figure 3b) considerable positional intermixing is found among rodents, megachiroptera and microchiroptera. Thus, unlike single attributes (Figure 3a,b) multiple attributes (Figure 3c-e) provide a more rational representation of parsimony and allow these to be viewed in three-dimensional plots.

\section{$\beta$-globin homology}

To build multiparametric 3-D phylogenetic trees based on sequence data for 12 species, we retrieved (see, materials and methods) complete amino acid sequence, coding nucleotide sequence and gene nucleotide sequence for $\beta$-globin from 11 vertebrates and a bivalve. In order to 


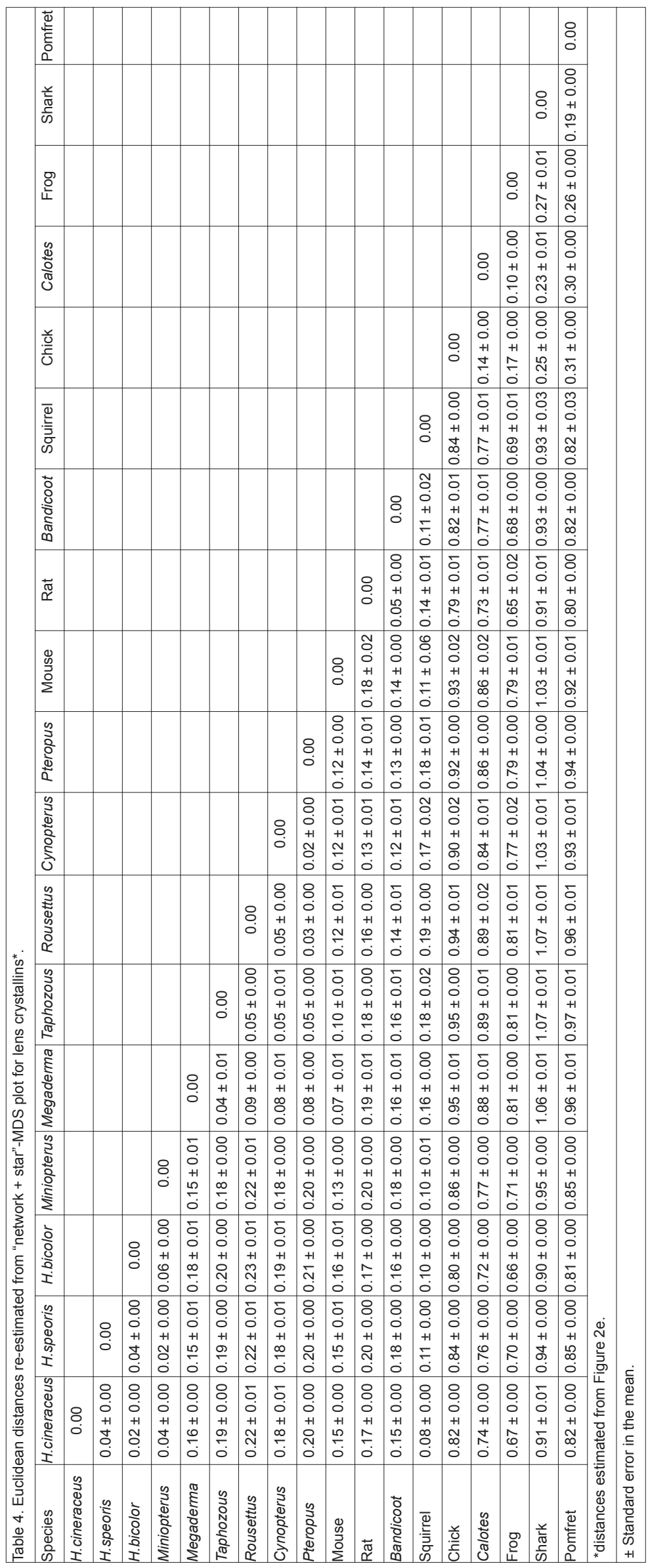

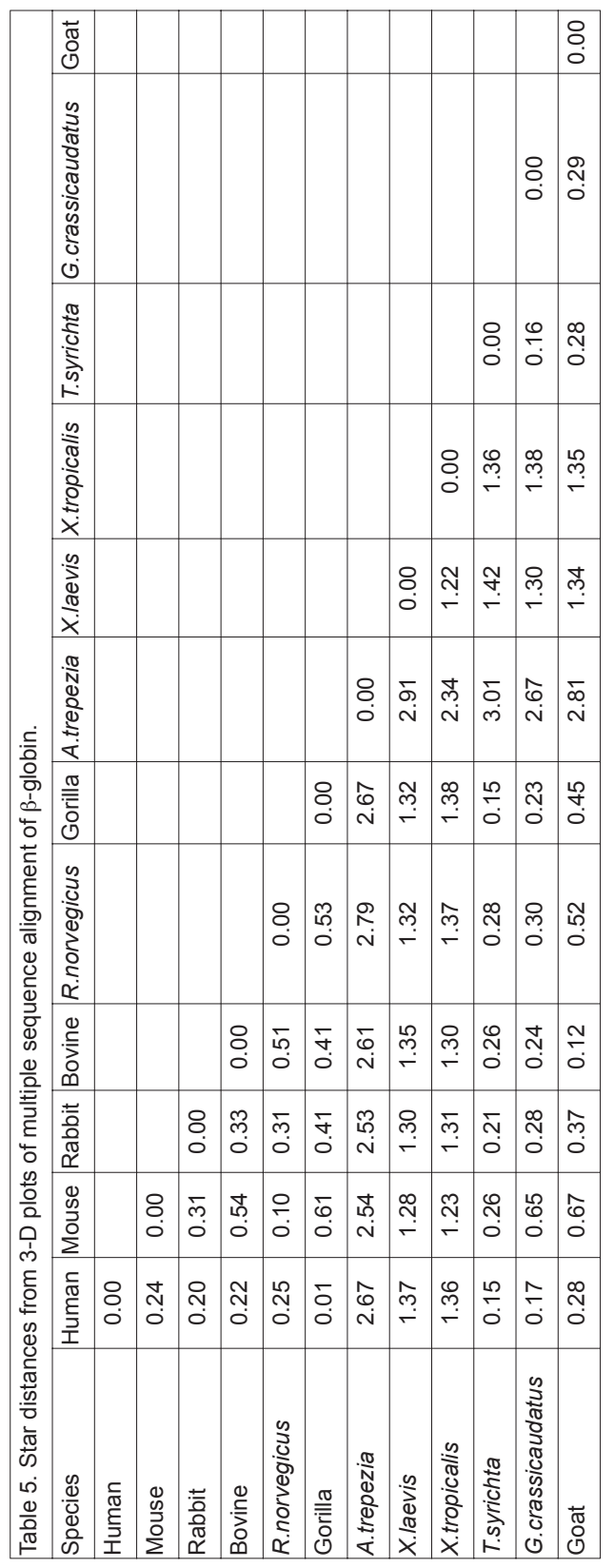




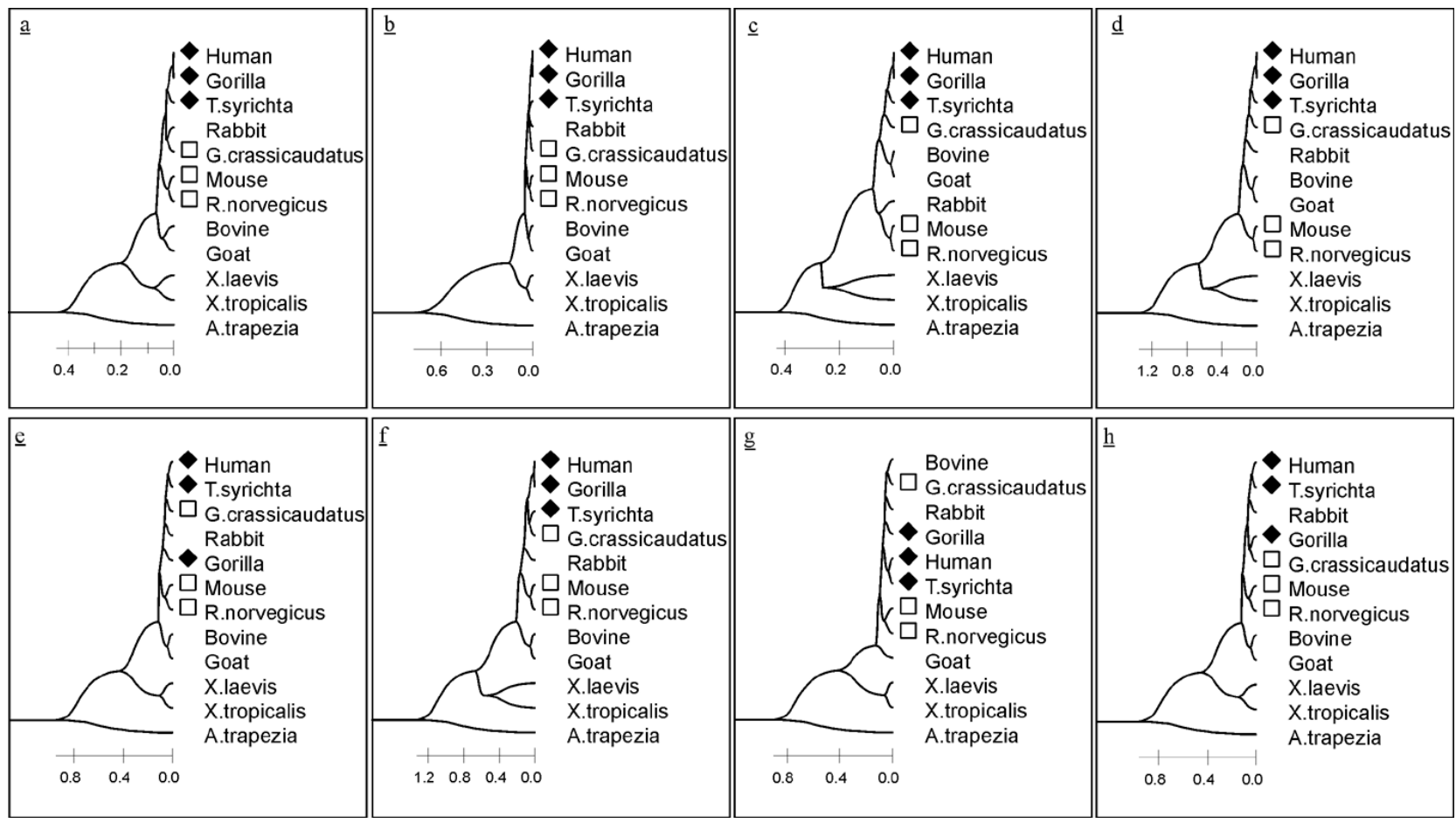

Figure 5. (a) $P$ values of multiple sequence alignment score for $\beta$-globin Amino acid, (b) $P$ values of multiple sequence alignment score for $\beta$-globin coding segments nucleotide sequence, (c) P values of multiple sequence alignment score for $\beta$-globin gene nucleotide sequence, (d) $\beta$-globin "star" distances (e) $\beta$-globin "network+star" distances (f) Re-estimated Euclidian distances from $\beta$-globin "star" MDS plot (g) Re-estimated Euclidian distances from $\beta$-globin "network" MDS plot (h) Re-estimated Euclidian distances from $\beta$-globin "network + star" MDS plot. 凹 Rodents, $\bullet$ Primates.

Table 6. "Network+star" distances from multiple sequence alignment of $\beta$-globin.

\begin{tabular}{|c|c|c|c|c|c|c|c|c|c|c|c|c|}
\hline Species & Human & Mouse & Rabbit & Bovine & R.norvegicus & Gorilla & A.trepezia & X.laevis & X.tropicalis & T.syrichta & $\begin{array}{l}\text { G.crassi- } \\
\text { caudatus }\end{array}$ & Goat \\
\hline Human & 0.00 & & & & & & & & & & & \\
\hline Mouse & $0.25 \pm 0.17$ & 0.00 & & & & & & & & & & \\
\hline Rabbit & $0.13 \pm 0.10$ & $\begin{array}{c}0.18 \pm \\
0.12\end{array}$ & 0.00 & & & & & & & & & \\
\hline Bovine & $0.17 \pm 0.12$ & $\begin{array}{c}0.26 \pm \\
0.22\end{array}$ & $\begin{array}{c}0.15 \pm \\
0.12\end{array}$ & 0.00 & & & & & & & & \\
\hline R.norvegicus & $0.21 \pm 0.15$ & $\begin{array}{c}0.13 \pm \\
0.18\end{array}$ & $\begin{array}{c}0.17 \pm \\
0.16\end{array}$ & $\begin{array}{c}0.21 \pm \\
0.21\end{array}$ & 0.00 & & & & & & & \\
\hline Gorilla & $0.14 \pm 0.13$ & $\begin{array}{c}0.26 \pm \\
0.20\end{array}$ & $\begin{array}{c}0.17 \pm \\
0.14\end{array}$ & $\begin{array}{c}0.18 \pm \\
0.15\end{array}$ & $0.24 \pm 0.24$ & 0.00 & & & & & & \\
\hline A.trepezia & $2.19 \pm 0.78$ & $\begin{array}{c}2.07 \pm \\
0.73\end{array}$ & $\begin{array}{c}2.13 \pm \\
0.74\end{array}$ & $\begin{array}{c}2.12 \pm \\
0.75\end{array}$ & $2.12 \pm 0.76$ & $2.11 \pm 0.77$ & 0.00 & & & & & \\
\hline X.laevis & $0.97 \pm 0.44$ & $\begin{array}{c}0.84 \pm \\
0.39\end{array}$ & $\begin{array}{c}0.91 \pm \\
0.39\end{array}$ & $\begin{array}{c}0.88 \pm \\
0.43\end{array}$ & $0.85 \pm 0.42$ & $\begin{array}{c}0.89 \pm \\
0.40\end{array}$ & $\begin{array}{c}1.65 \pm \\
0.71\end{array}$ & 0.00 & & & & \\
\hline X.tropicalis & $0.98 \pm 0.43$ & $\begin{array}{c}0.82 \pm \\
0.40\end{array}$ & $\begin{array}{c}0.89 \pm \\
0.41\end{array}$ & $\begin{array}{c}0.89 \pm \\
0.41\end{array}$ & $0.91 \pm 0.38$ & $\begin{array}{c}0.88 \pm \\
0.44\end{array}$ & $\begin{array}{c}1.59 \pm \\
0.57\end{array}$ & $0.30 \pm 0.46$ & 0.00 & & & \\
\hline T.syrichta & $0.08 \pm 0.10$ & $\begin{array}{c}0.27 \pm \\
0.17\end{array}$ & $\begin{array}{c}0.15 \pm \\
0.15\end{array}$ & $0.18 \pm 0.12$ & $0.20 \pm 0.13$ & $\begin{array}{l}0.20 \pm \\
0.15\end{array}$ & $\begin{array}{c}2.20 \pm \\
0.80\end{array}$ & $0.95 \pm 0.45$ & $0.99 \pm 0.39$ & 0.00 & & \\
\hline $\begin{array}{l}\text { G.crassi- } \\
\text { caudatus }\end{array}$ & $\begin{array}{c}0.11 \pm \\
0.12\end{array}$ & $\begin{array}{c}0.25 \pm \\
0.21\end{array}$ & $\begin{array}{c}0.14 \pm \\
0.12\end{array}$ & $\begin{array}{c}0.13 \pm \\
0.08\end{array}$ & $0.22 \pm 0.17$ & $\begin{array}{c}0.14 \pm \\
0.10\end{array}$ & $1.66 \pm 0.69$ & $0.91 \pm 0.42$ & $0.92 \pm 0.43$ & $\begin{array}{c}0.13 \pm \\
0.14\end{array}$ & 0.00 & \\
\hline Goat & $0.22 \pm 0.15$ & $\begin{array}{c}0.30 \pm \\
0.25\end{array}$ & $\begin{array}{c}0.21 \pm \\
0.18\end{array}$ & $\begin{array}{c}0.09 \pm \\
0.10\end{array}$ & $0.20 \pm 0.22$ & $\begin{array}{c}0.22 \pm \\
0.20\end{array}$ & $\begin{array}{c}1.64 \pm \\
0.71\end{array}$ & $0.84 \pm 0.45$ & $0.89 \pm 0.40$ & $\begin{array}{c}0.83 \pm \\
0.41\end{array}$ & $\begin{array}{c}0.17 \pm \\
0.12\end{array}$ & 0.00 \\
\hline
\end{tabular}



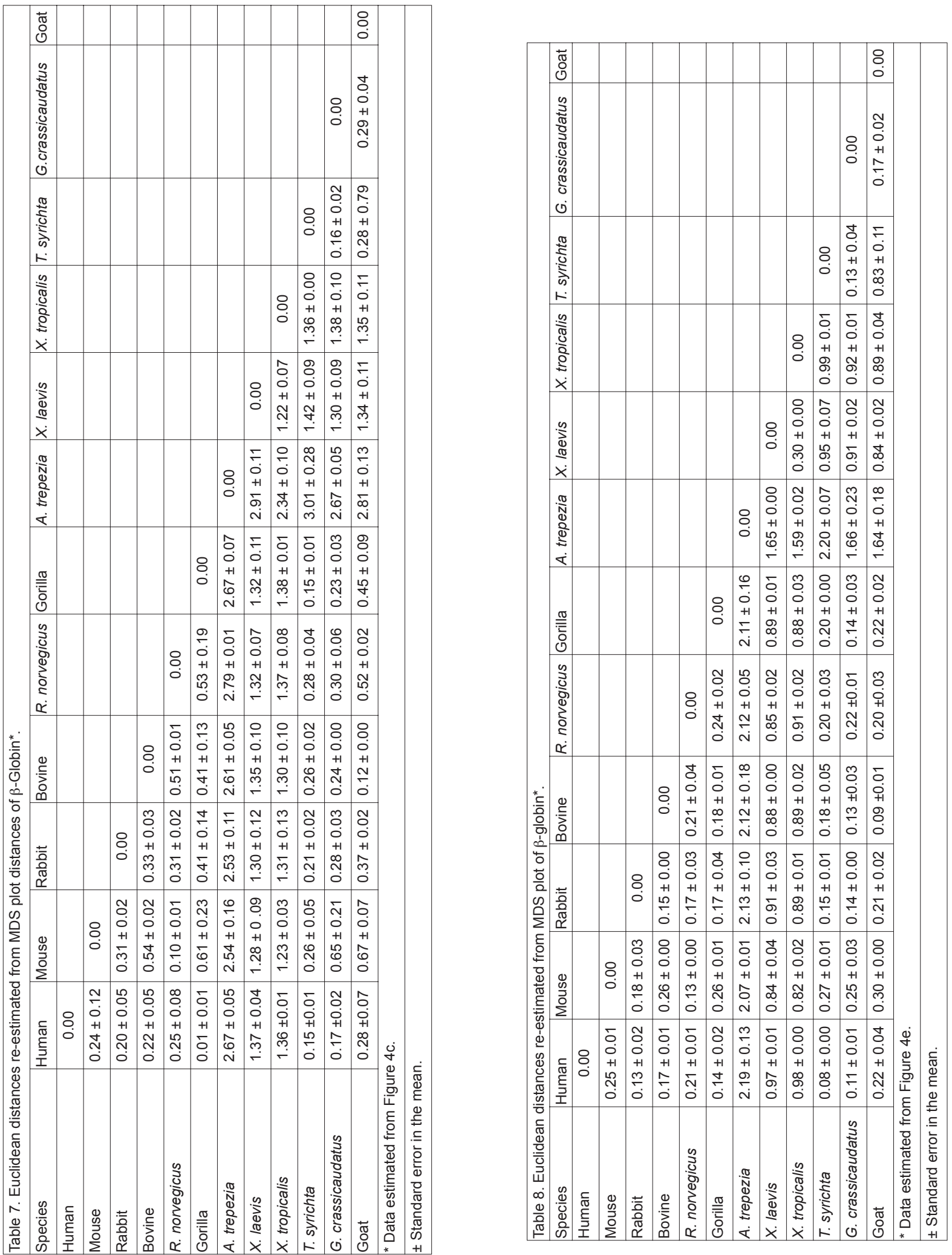
restrict the analysis to the phene-relevant portion of $\beta$ globin, the beginning of the gene was taken from the 5 proximal TATA box and terminating with polyadenylation signal 3' of the coding sequence. We carried out the multiple sequence alignment (MSA) in a $12 \times 12$ matrix separately for the polypeptide, coding sequence and the gene to estimate the percent similarity and $P$ values (see methods, computed data not shown). With reference to the species positioned at $(0,0,0)$, the $P$ values of remaining 11 species were plotted in a 3-D along the $x$ (amino acid sequence)- $y$ - (gene nucleotide sequence) and $z$ - (coding nucleotide sequence) axes, thereby yielding 12 plots and, as representative plots we show those for human (Figure 4a), mouse (not shown) Xenopus laevis (Figure 4b) and the bivalve Anadara trepezia (not shown). From these, Euclidean "star" (Table 5) and "network" distances were estimated (see, methods). Table 6 summarizes "network + star" distances and 2-D phylogenetic trees were constructed (Figure $5 \mathrm{~d} \mathrm{e}$ ); the relative species positions in the tree for "network" distances alone is similar to that in Figure $5 \mathrm{e}$, however the estimated evolutionary distances differ between the two trees. Therefore, we have subjected both data sets to bootstrap analysis and find that the trees fit the data with probability of $0.84 \pm 0.032$ for "network + star" distances as compared to $0.80 \pm 0.035$ for "network" distances alone.

Euclidean distance data in Tables 5 and 6 were subjected to MDS (Figure 4f). and the re-estimated Euclidean distances (Table 7) were used to construct a phylogenetic tree (Figure 4d). However, the bi-directional "star" distances being identical, bootstrap was not necessary. After transposing the branching pattern (Figure 5f) to the MDS plot, we obtain a 3-D tree (Figure $4 \mathrm{f}$ ) in which two branches originating from the stem reach the bivalve and vertebrates, respectively. The vertebrate branch bifurcates between Xenopus sp. and mammals with the latter branching off to ungulates, rodents, the rabbit, the dormouse and primates, in that order. Except for the switched positions between ungulates and rodents, the 2-D trees are similar for Euclidean "star" and "star-MDS" distances (Figure 5d, and e). When the mammalian branch is magnified (Figure $4 d$ ) it sub-branches sequentially into ungulates, rodents, rabbit and primates with Human and Gorilla as a separate blossom from the Tarsius sp. and dormouse. MDS based on Euclidean "network" distances alone (not shown) gave a tree (Figure 5h) which is considerably different from that based on original "network" distances (Figure 5e) data were Euclidean "star + network" distances (Table 6) were placed in $\mathrm{x}, \mathrm{y}$ and $\mathrm{z}$ space by MDS and the 2-D tree constructed from the reestimated Euclidean distances (Table 8) by unweighted pair grouping (Figure $5 \mathrm{~g}$ ) was transposed over MDS plot to obtain 3-D phylogenetic trees (Figure 4e,f). The mammalian branching pattern is somewhat different with "star-MDS". Thus, ungulates lead to rodents and gorilla-dormouse pair, followed by the rabbit and primates $T$. syrichta and the human. Furthermore, the mammalian $\beta$-globin blossom exhibits ungulates, rat and mouse as distant from primates among whom the Homo sapiens share closeness with either gorilla or Tarsius.

Finally, the $\beta$-globin phylogenetic tree based on the amino acid sequence (Figure $5 \mathrm{a}$ ) is similar to that using coding nucleotide sequence (Figure $5 \mathrm{~b}$ ). In contrast, the tree for gene nucleotide sequence (Figure $5 \mathrm{c}$ ) is substantially different with the rat, mouse and rabbit positioned farther to primates than ungulates. Thus, as expected, mutations appear to change the gene nucleotide sequence, inclusive of 5' and 3' noncoding regions and introns, and determine the phylogenetic distance at molecular level.

One of the issue concerns the choice of Euclidean distances as compared to the Mahalanobis distance, which is a squared distance between two points in a multidimensional space. Earlier (Milner et al., 2003), we have examined the 3-D positioning of 8 vertebrates on the basis of the Mahalanobis distance that did not give satisfactory fits. However, for a heterogeneous population of organisms, this method should be kept in view. For positioning 8 vertebrates in 3-D space, we also used (Milner et al., 2003) a Sequential Positioning method, which gave good fits but requires extensive computations and the software program, is now being developed.

\section{Acknowledgements}

We thank Profs B.K. Kale and M.B. Rajarshi from the Department of Statistics, University of Pune, India, and Dr. N.V. Joshi, CES, Indian Institute of Science, Bangalore, India, Prof. S.K. Saidapur, Department of Zoology, Karnatak University, Dharwad, India for critical discussions and encouragement. This work is a part of MM's Ph.D. thesis and supported by CSIR (SPM).

\section{References}

Bansode, A.G. 1985. Evolutionary relationship in Chiroptera: Biochemical analysis. Ph.D. Thesis, pp. 1-163. University of Poona, Pune, India.

Brown, W.M., George, M. and Wilson A.C. 1979. Rapid evolution of animal mitochondrial DNA. Proc. Nat. Acad. Sci. USA. 76: 1967-1971.

Darwin, C. 1859. On the Origin of Species by Means of Natural Selection, or the Preservation of Favored in the Struggle for Life. John Murray, London. [1964. facsimile edition. E.Mayr, ed. Harvard Univ. Press, Cambridge, Mass.]

Efron, B. 1979. Bootstrap methods:Another look at the jackknife. Ann.Stat. 7:1-26.

Felsenstein, J. 1985. Confidence limits on phylogenies: An approach using the bootstrap. Evolution. 39: 783-791.

Fitch, W.M. and Margoliash, E. 1967. Construction of phylogenetic trees. Science. 155: 279-284.

Fitch, W.M. and Margoliash, E. 1970. The usefulness of amino acid and nucleotide sequences in evolutionary studies. Evol. Biol. 4: 67-109.

Honacki, J.H., Kinman, K.E. and Koeppel, J.W. 1982. Mammal species of the world, A taxonomic and geographic references. Allen press Inc. \& the Association of Systematics collections, Lawrence, Kansas, U.S.A.

King, J.L. and Jukes, T.H. 1969. Non-Darwinian evolution. Science. 164: 788-795.

Milner, M., Patwardhan, V., Bansode. A.G., Nevagi, S.A., Kulkarni, S., Kamakaka, R. and Modak, S.P. 2003. Constructing 3-D phylogenetic trees. Curr. Sci. 85: 1471-1478. 
Mayr, E. 1970. Population, Species and Evolution. Harvard University Press, Cambridge, Mass., pp.1-453.

Schadt, E.K., Sinsheimer, J. and Lange, K. 1998. Computational advances in maximum likelihood methods for molecular phylogeny. Genome Res. 8: 222-243.

Suthers, R.A., Wimsatt, W.A. (Ed.) 1970. Biology of bats. Vol. 1: pp. 265-304, Academic press, New York.

Patwardhan, V.G. and Modak, S.P. 1992. Physicochemical characterization and phylogenetic comparison of fish lens proteins. Ind. J. Biochem. Biophys. 29: 498-507.

Patwardhan, V. 1992. Phylogeny of fish lens crystallins. Ph.D. Thesis, pp.1-98, University of Poona, Pune, India.

Patwardhan, V.G., Jaswany, V.L., Pal, J.K. and Modak, S.P. 1995. Lens protein Phylogeny: Immunocrossreactivity of vertebrate lens antigens to antishark antibody. Ind. J. Biochem. Biophys. 32: 21-31.
Rambaut, A., Robertson, D.L., Pybus, O.G., Peeters, M. and Holmes, E.C. 2001. Human immunodeficiency viruses. Phylogeny and origin of HIV-1. Nature. 410: 1047-1048.

Romer, A.S. Vertebrate Paleontology. 1947. University of Chicago Press, 3rd ed.

Kumar, S., Tamura, K., Jakobsen, I.B and Nei, M. 2001. MEGA2: Molecular Evolutionary Genetics Analysis software. Bioinformatics. 17: 1244 -1245.

Thompson, J.D., Higgins, D.G. and Gibson, T.J. 1994. CLUSTALW-improve the sensitivity of progressive multiple sequence alignment through sequence weighting, position specific gap penalties and weight matrix choice. Nucl. Acids Res. 22: 4673-4680.

Upholt, W.B. 1977. Estimation of DNA sequence divergence from comparison of restriction endonuclease digests. Nucl. Acids Res. 4: 1257-1265. 


\section{Further Reading}

Caister Academic Press is a leading academic publisher of advanced texts in microbiology, molecular biology and medical research. Full details of all our publications at caister.com

- MALDI-TOF Mass Spectrometry in Microbiology Edited by: M Kostrzewa, S Schubert (2016) www.caister.com/malditof

- Aspergillus and Penicillium in the Post-genomic Era Edited by: RP Vries, IB Gelber, MR Andersen (2016) www.caister.com/aspergillus2

- The Bacteriocins: Current Knowledge and Future Prospects Edited by: RL Dorit, SM Roy, MA Riley (2016)

www.caister.com/bacteriocins

- Omics in Plant Disease Resistance Edited by: V Bhadauria (2016) www.caister.com/opd

- Acidophiles: Life in Extremely Acidic Environments Edited by: R Quatrini, DB Johnson (2016) www.caister.com/acidophiles

- Climate Change and Microbial Ecology: Current Research and Future Trend

Edited by: J Marxsen (2016)

www.caister.com/climate

- Biofilms in Bioremediation: Current Research and Emerging Technologies

Edited by: G Lear (2016)

www.caister.com/biorem

- Microalgae: Current Research and Applications Edited by: MN Tsaloglou (2016) www.caister.com/microalgae

- Gas Plasma Sterilization in Microbiology: Theory, Applications, Pitfalls and New Perspectives Edited by: H Shintani, A Sakudo (2016) www.caister.com/gasplasma

- Virus Evolution: Current Research and Future Directions Edited by: SC Weaver, M Denison, M Roossinck, et al. (2016) www.caister.com/virusevol

- Arboviruses: Molecular Biology, Evolution and Control Edited by: N Vasilakis, DJ Gubler (2016) www.caister.com/arbo

- Shigella: Molecular and Cellular Biology Edited by: WD Picking, WL Picking (2016) www.caister.com/shigella

-Aquatic Biofilms: Ecology, Water Quality and Wastewater Treatment

Edited by: AM Romaní, H Guasch, MD Balaguer (2016)

www.caister.com/aquaticbiofilms

- Alphaviruses: Current Biology

Edited by: S Mahalingam, L Herrero, B Herring (2016)

www.caister.com/alpha

- Thermophilic Microorganisms

Edited by: F Li (2015)

www.caister.com/thermophile
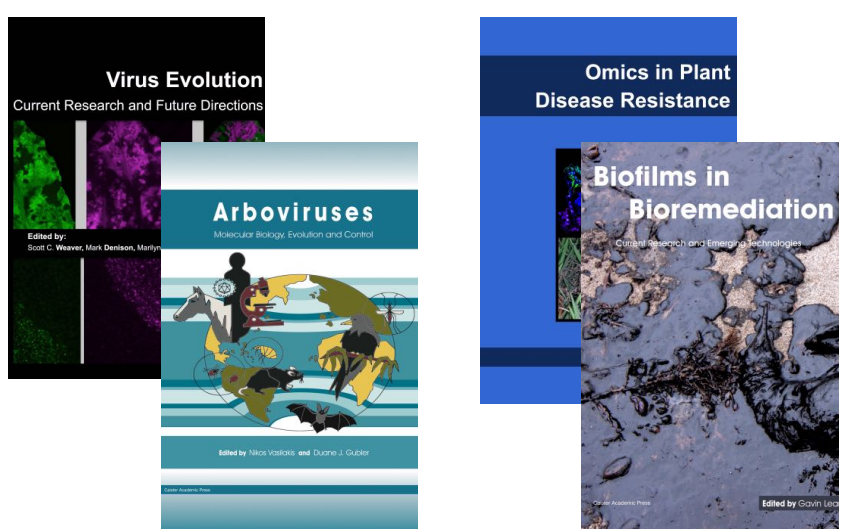
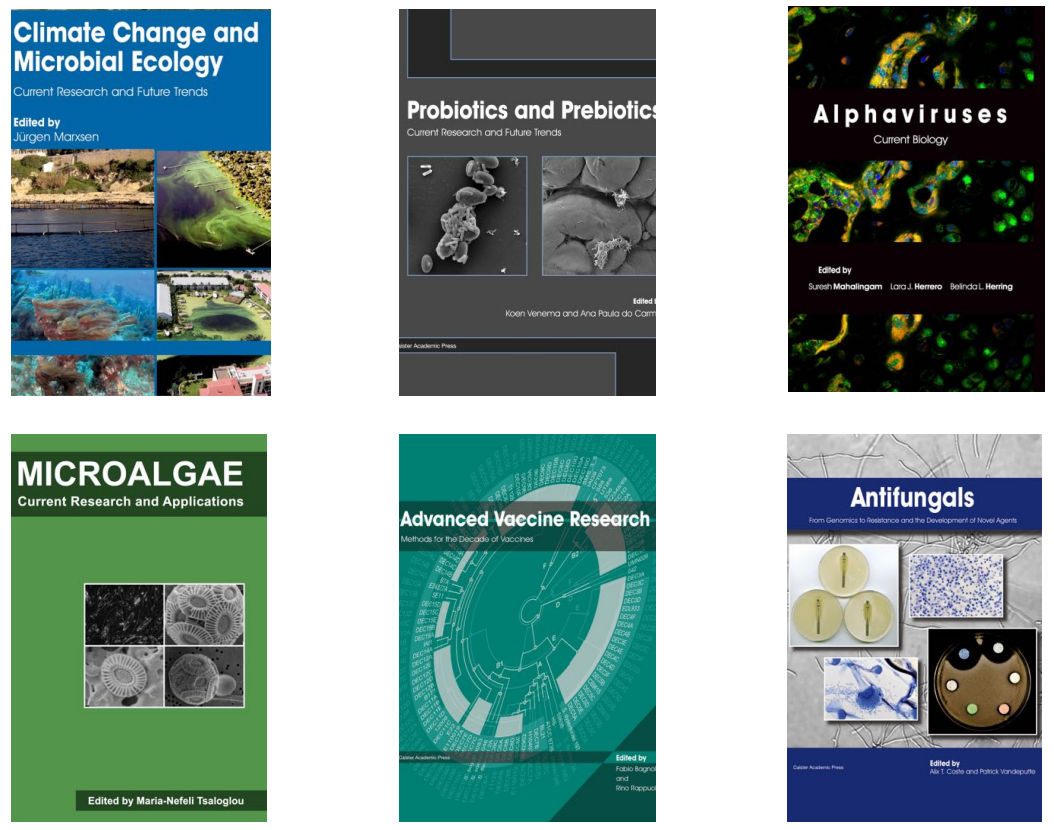

- Flow Cytometry in Microbiology: Technology and Applications Edited by: MG Wilkinson (2015) www.caister.com/flow

- Probiotics and Prebiotics: Current Research and Future Trends Edited by: K Venema, AP Carmo (2015) www.caister.com/probiotics

- Epigenetics: Current Research and Emerging Trends Edited by: BP Chadwick (2015) www.caister.com/epigenetics2015

- Corynebacterium glutamicum: From Systems Biology to Biotechnological Applications

Edited by: A Burkovski (2015)

www.caister.com/cory2

- Advanced Vaccine Research Methods for the Decade of Vaccines

Edited by: F Bagnoli, R Rappuoli (2015)

www.caister.com/vaccines

- Antifungals: From Genomics to Resistance and the Development of Novel Agents

Edited by: AT Coste, P Vandeputte (2015)

www.caister.com/antifungals

- Bacteria-Plant Interactions: Advanced Research and Future Trends Edited by: J Murillo, BA Vinatzer, RW Jackson, et al. (2015) www.caister.com/bacteria-plant

\section{- Aeromonas}

Edited by: J Graf (2015)

www.caister.com/aeromonas

- Antibiotics: Current Innovations and Future Trends

Edited by: S Sánchez, AL Demain (2015)

www.caister.com/antibiotics

- Leishmania: Current Biology and Contro Edited by: S Adak, R Datta (2015) www.caister.com/leish2

- Acanthamoeba: Biology and Pathogenesis (2nd edition) Author: NA Khan (2015)

www.caister.com/acanthamoeba2

- Microarrays: Current Technology, Innovations and Applications Edited by: Z He (2014)

www.caister.com/microarrays2

- Metagenomics of the Microbial Nitrogen Cycle: Theory, Methods and Applications

Edited by: D Marco (2014)

www.caister.com/n2 